\title{
Purificação de amiloglicosidase de Aspergillus niger
}

\section{Purification of amyloglucosidase from Aspergillus niger}

\author{
Ana Paula Manera ${ }^{1}$; Simone Meinhardt²; Susana Juliano Kali1 ${ }^{3 *}$
}

\section{Resumo}

\begin{abstract}
Neste trabalho foram realizados testes para determinação das melhores condições de purificação da amiloglicosidase de Aspergillus niger NRRL 3122, usando cromatografia de troca iônica em coluna de leito fixo. Os testes de purificação foram conduzidos em coluna contendo resina aniônica DEAEcelulose. Para maximizar as condições de purificação foram testadas as variáveis velocidade de alimentação $(46$ e $8 \mathrm{~cm} / \mathrm{h})$ e temperatura de operação $\left(25\right.$ e $\left.10^{\circ} \mathrm{C}\right)$. O melhor resultado foi observado quando empregou-se velocidade de alimentação de $8 \mathrm{~cm} / \mathrm{h}$ e temperatura de $10^{\circ} \mathrm{C}$, resultando num fator de purificação de 9,9 vezes e uma recuperação de $47,6 \%$.
\end{abstract}

Palavras-chave: DEAE-celulose. Enzima. Temperatura.

\begin{abstract}
In this work, test were carried out to determine the best conditions for the purification of amyloglucosidase from Aspergillus niger NRRL 3122, using a fixed-bed ion exchange chromatography column. The tests were conducted in a purification column containing anion resin DEAE-cellulose. To maximize the purification conditions, were used as variable parameters feeding speed $(46$ and $8 \mathrm{~cm} / \mathrm{h}$ ) and operating temperature $\left(25\right.$ and $\left.10^{\circ} \mathrm{C}\right)$. The best result was observed when a feeding speed of $8 \mathrm{~cm} / \mathrm{h}$ was employed at a temperature of $10^{\circ} \mathrm{C}$, resulting in a purification factor of 9.9 -fold and a recovery of $47.6 \%$.
\end{abstract}

Key words: DEAE-cellulose. Enzyme. Temperature.

Amilases $\quad(\alpha$-amilase, $\quad \beta$-amilase e capacidade para hidrolisar ao mesmo tempo as amiloglicosidase) estão entre as enzimas mais ligações $\alpha-1,4$ e $\alpha-1,6$ (PANDEY et al., 2000). Esta importantes obtidas através de processos enzima é um importante biocatalisador industrial biotecnológicos, sendo que as de origem microbiana empregado na produção de xaropes de glicose substituíram a hidrólise química do amido além a partir de matérias-primas amiláceas. Elas são de serem potencialmente úteis nas indústrias de depois das proteases, as enzimas de maior venda fármacos e química fina (PANDEY ET al., 2000).

A amiloglicosidase (EC 3.2.1.3) é uma exoenzima que libera unidades de glicose a partir da extremidade não redutora da amilose, amilopectina e glicogênio. É a única enzima amilolítica com e distribuição mundial (CHEN; ZHANG; ZHOU, 2005). Esta enzima é produzida por microrganismos, principalmente pelos fungos filamentosos Aspergillus niger e Rhizopus sp. (GONZALES et al. 1998, SILVEIRA et al., 2006). A preferência

\footnotetext{
1 Engenheira de Alimentos, Escola de Química e de Alimentos. Universidade Federal do Rio Grande, FURG. Rua Engenheiro Alfredo Huch, 475, CEP: 96201-900, Rio Grande, RS. E-mail: anapaulamanera@yahoo.com.br

2 Engenheira Química; Escola de Química e de Alimentos. Universidade Federal do Rio Grande, FURG. Rua Engenheiro Alfredo Huch, 475, CEP: 96201-900, Rio Grande, RS. E-mail: simone.meinhardt@gmail.com.br

3 Prof ${ }^{\mathrm{a}}$. Dr ${ }^{\mathrm{a}}$. da Escola de Química e de Alimentos. Universidade Federal do Rio Grande, FURG. Rua Engenheiro Alfredo Huch, 475, CEP: 96201-900, Rio Grande, RS. E-mail: dqmsjk@furg.br

* Autor para correspondência
} 
das indústrias de processamento de amido, por amiloglicosidases destas fontes se deve ao fato de que estes microrganismos são reconhecidos como seguros sendo aceitos pela Food and Drug Administration (FDA) (MICHELIN et al., 2008).

Quando enzimas são produzidas por meio de processos biotecnológicos, o meio de cultivo frequentemente contém outras enzimas e contaminantes, sendo necessárias operações subseqüentes de recuperação, purificação e concentração (downstream processing), obtendo assim, a enzima quimicamente pura e com o máximo de atividade específica, seja para uso em processos industriais ou para estudos em escala de laboratório. Em muitos processos, os custos com estas operações podem atingir até $80 \%$ dos custos totais de produção (WENZIG et al., 1993).

A literatura destaca o emprego de algumas técnicas de purificação para a amiloglicosidase, como fracionamento com sulfato de amônio; cromatografia de troca iônica, de interação hidrofóbica e por afinidade; e extração por sistema aquoso bifásico (CHEN; ZHANG; ZHOU, 2005; MICHELIN et al., 2008). Os processos cromatográficos são extensamente usados com alto desempenho na etapa de purificação de produtos biotecnológicos. A cromatografia de troca iônica é a técnica mais comumente empregada na separação de proteínas e enzimas, além disso, é utilizada com muita efetividade pelas indústrias bioquímicas e farmacêuticas para o escalonamento dos processos de isolamento de proteínas (GERBERDING; BYERS, 1998). Este método, se baseia no princípio da reversibilidade das atrações eletrostáticas de uma molécula carregada em relação a uma matriz sólida com grupos com cargas opostas e ligados covalentemente à matriz (LEVISON, 2003).

Para projetar um efetivo e seletivo procedimento cromatográfico de separação e purificação é necessário ter conhecimento do efeito das condições operacionais que influenciam na adsorção, como $\mathrm{pH}$, temperatura, concentração da molécula carregada e velocidade do fluxo do processo (BAUTISTA; MARTÍNEZ; ARACIL, 1999), de modo a maximizar a purificação sem prejuízos na recuperação.

Este trabalho teve como objetivo, purificar a enzima amiloglicosidase de Aspergillus niger NRRL 3122 através de cromatografia de troca iônica em coluna de leito fixo avaliando o efeito da temperatura de operação e da velocidade de alimentação, de modo a obter elevado fator de purificação e minimizar perdas da enzima.

O fungo Aspergillus niger NRRL 3122 foi empregado para produção da enzima amiloglicosidase. O microrganismo foi mantido a $4^{\circ} \mathrm{C}$ em tubo de ensaio contendo ágar batata dextrose inclinado. $\mathrm{O}$ inóculo foi feito em Erlenmeyers contendo ágar batata dextrose e incubados a $30^{\circ} \mathrm{C}$ por $72 \mathrm{~h}$. A amiloglicosidase foi produzida por cultivo em estado sólido, em Erlenmeyers, contendo $85 \%$ de farelo de arroz desengordurado e $15 \%$ de casca de arroz, acrescido de $\mathrm{KH}_{2} \mathrm{PO}_{4}, \mathrm{MgSO}_{4}$ e $\mathrm{NH}_{2} \mathrm{CONH}_{2}$, nas concentrações de 2,0 g/L, 1,0 g/L e $1,8 \mathrm{~g} / \mathrm{L}$, respectivamente. A umidade final do meio foi ajustada para 50\% e o pH para 5,0 com a adição de $\mathrm{HCl}$ 0,4 M. O meio foi esterilizado em autoclave a $121^{\circ} \mathrm{C}$ por $15 \mathrm{~min}$. O substrato foi inoculado com

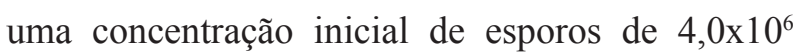
esporos/g. Os frascos foram incubados a $30^{\circ} \mathrm{C}$ por 72 h (COSTA; MARTÍNEZ; ARACIL, 1998).

A enzima foi extraída do meio de cultivo com água destilada na proporção de 1:10 (p/v). A extração foi realizada a $25^{\circ} \mathrm{C}, 200 \mathrm{rpm}$ por $3 \mathrm{~h}$ (GHILDYAL et al., 1991). A suspensão foi filtrada para remoção dos sólidos e o extrato contendo a enzima foi utilizado nos ensaios de purificação.

Em todos os ensaios de purificação foi utilizada uma coluna $\mathrm{C} 10 / 20$ (Pharmacia ${ }^{\circledR}$ ), com $1 \mathrm{~cm}$ de diâmetro e $20 \mathrm{~cm}$ de altura, empacotada com $10 \mathrm{~mL}$ de resina aniônica DEAE-celulose $\left(\right.$ Sigma $\left.^{\circledR}\right)$. Ao início de cada teste a resina foi lavada com tampão Tris-HCl 0,025 M pH 8,0 até atingir o equilíbrio, $\mathrm{pH}$ este definido por Manera et al. (2008) como 
sendo o melhor pH de adsorção desta enzima pela resina DEAE-celulose.

Para purificação da enzima, $6 \mathrm{~mL}$ do extrato enzimático foram alimentados à coluna empacotada com $10 \mathrm{~cm}$ da resina DEAE-celulose. Em seguida a coluna foi lavada para retornar a linha base, eliminando-se as proteínas não adsorvidas. A eluição foi realizada com $\mathrm{NaCl}$ em tampão Tris- $\mathrm{HCl} 0,025$ $\mathrm{M} \mathrm{pH} \mathrm{8,0} \mathrm{na} \mathrm{forma} \mathrm{de} \mathrm{gradiente} \mathrm{linear} \mathrm{crescente}$ até a concentração de 1,0 M. Foram coletadas na

\section{Atividade da enzima purificada \\ $\mathrm{FP}=\frac{\overline{\text { Concentração de proteina na enzima purificada }}}{\text { Atividade do extrato enzimático }}$} Concentração de proteina no extrato enzimático

$$
\mathrm{R}(\%)=\frac{\text { Atividade da enzima purificada }}{\text { Atividade do extrato enzimático }} \times 100
$$

O fator de purificação considera o aumento na atividade específica da enzima após a etapa de purificação e a recuperação é a porcentagem da enzima recuperada em relação à enzima alimentada.

A atividade enzimática foi determinada pela quantidade de glicose produzida pela ação da enzima. Foram adicionados $0,5 \mathrm{~mL}$ de amostra previamente diluída em $12,5 \mathrm{~mL}$ de solução de amido $\left(4 \%\right.$ p/v) pH 4,2 a $60^{\circ} \mathrm{C}$ por $60 \mathrm{~min}$, a reação foi paralisada por ebulição a $100^{\circ} \mathrm{C}$ por $5 \mathrm{~min}$ (GOUVEIA; KILIKIAN, 2000). A quantidade de glicose liberada foi quantificada pelo método do ácido 3,5-dinitrossalicílico (MILLER, 1959). Uma saída da coluna frações de $2,6 \mathrm{~mL}$ determinandose a absorbância a $280 \mathrm{~nm}$, a atividade enzimática e a concentração de proteínas. Ao final calculouse a recuperação e o fator de purificação. As temperaturas de operação empregadas foram 25 e $10^{\circ} \mathrm{C}$ e as velocidades de alimentação foram 46 e 8 $\mathrm{cm} / \mathrm{h}$.

Para avaliação dos resultados em termos de fator de purificação (FP) e recuperação $(\mathrm{R})$, foram utilizadas as Equações 1 e 2:

unidade de atividade enzimática foi definida como a quantidade de enzima necessária para liberar $1 \mu \mathrm{mol}$ de glicose por minuto sob as condições do ensaio. A concentração total de proteínas foi determinada pelo método de Lowry et al. (1951) usando albumina de soro bovino como proteína padrão. O conteúdo de proteína eluído na coluna foi monitorado por leitura de absorbância a $280 \mathrm{~nm}$.

Foram realizados ensaios para purificação da enzima amiloglicosidase avaliando o efeito da velocidade de alimentação e da temperatura na recuperação e no fator de purificação, conforme (Tabela 1). 
Tabela 1. Condições dos ensaios de purificação e resposta do fator de purificação e recuperação da amiloglicosidase de Aspergillus niger NRRL 3122 usando resina DEAE-celulose em coluna de leito fixo.

\begin{tabular}{lcccc}
\hline Ensaios & $\begin{array}{c}\text { Velocidade de } \\
\text { alimentação }(\mathbf{c m} / \mathbf{h})\end{array}$ & $\begin{array}{c}\text { Temperatura } \\
\text { de operação }\left({ }^{\mathbf{0}} \mathbf{C}\right)\end{array}$ & Fator de Purificação & Recuperação(\%) \\
\hline 1 & 46 & 25 & 1,94 & 0,94 \\
2 & 8 & 25 & 0,25 & 20,60 \\
3 & 8 & 10 & 9,90 & 47,60 \\
4 & 46 & 10 & 0,17 & 5,50 \\
\hline
\end{tabular}

Fonte:Elabora pelos autores.

No ensaio 1 a velocidade de alimentação foi $46 \mathrm{~cm} / \mathrm{h}$ e a temperatura de operação foi $25^{\circ} \mathrm{C}$, estas condições resultaram em um baixo fator de purificação (1,94 vezes) e uma baixa recuperação $(0,94 \%)$. A fim de se obter melhores resultados para as respostas fator de purificação e recuperação, realizou-se um segundo ensaio, onde manteve-se a temperatura de $25^{\circ} \mathrm{C}$ e diminui-se a velocidade de alimentação para $8 \mathrm{~cm} / \mathrm{h}$. Com a diminuição da velocidade de alimentação aumenta-se o tempo de contato da enzima com a resina favorecendo a adsorção. As respostas para o ensaio 2 foram 0,25 vezes e $20,6 \%$, para o fator de purificação e recuperação, respectivamente. Observou-se que diminuindo a velocidade de alimentação houve um incremento na recuperação, ou seja, do total da enzima alimentada 20,6\% foi recuperada, já o fator de purificação diminui, pois outras proteínas contaminantes também são melhor absorvidas, obtendo-se na eluição a enzima com menor atividade específica.

Visando aumentar o fator de purificação e melhorar a recuperação, realizou-se um terceiro ensaio, optou-se por manter a velocidade de alimentação em $8 \mathrm{~cm} / \mathrm{h}$ e diminuir a temperatura para $10^{\circ} \mathrm{C}$. A temperatura de $25^{\circ} \mathrm{C}$ é uma temperatura conveniente para processos industriais já que se assemelha a temperatura ambiente, e Manera et al. (2008), estudaram o efeito da temperatura na adsorção desta enzima pela resina DEAE-celulose, as temperaturas testadas variaram de 15 a $25^{\circ} \mathrm{C}$. Os ensaios foram realizados em shaker e a solução contendo a amiloglicosidase e a resina foi mantida a temperatura constante sob agitação. Os autores observaram que a temperatura de $25^{\circ} \mathrm{C}$ favoreceu a adsorção da enzima, ao passo que nas temperaturas inferiores a enzima foi menos adsorvida, porém, nestes ensaios de adsorção a enzima não entra em contato com o $\mathrm{NaCl}$, o qual é empregado na purificação, na etapa de eluição, realizada na forma de gradiente linear, este sal pode proporcionar uma condição desnaturante, fato este agravado com o aumento da temperatura.

O FP obtido no terceiro ensaio foi de 9,9 vezes e a recuperação foi de $47,6 \%$. Nas condições deste ensaio tanto o fator de purificação quanto a recuperação da enzima foram favorecidos, apesar da temperatura de $10^{\circ} \mathrm{C}$ não favorecer tanto a adsorção ela preserva mais a estabilidade conformacional da enzima.

Visando o escalonamento industrial deste processo, com o intuito de aumentar a produtividade, realizou-se um quarto ensaio aumentando a velocidade de alimentação. Empregou-se novamente $46 \mathrm{~cm} / \mathrm{h}$ e manteve-se a temperatura de $10^{\circ} \mathrm{C}$. Os resultados diminuíram drasticamente tanto para o fator de purificação $(0,17$ vezes $)$ quanto para a recuperação $(5,5 \%)$, comprovando que a menor velocidade de alimentação favorece a adsorção da enzima pela resina. Mesmo resultando em aumento na produtividade com o aumento na velocidade, observou-se que a etapa de purificação do bioproduto foi depreciada. 
De acordo com os resultados obtidos neste trabalho, tanto o fator de purificação quanto a recuperação da enzima apresentaram um substancial ganho ao diminuir a velocidade de alimentação de $46 \mathrm{~cm} / \mathrm{h}$ para $8 \mathrm{~cm} / \mathrm{h}$ e diminuir a temperatura de $25^{\circ} \mathrm{C}$ para $10^{\circ} \mathrm{C}$. O fator de purificação variou de 0,17 (ensaio 4) a 9,90 vezes (ensaio 3) e o rendimento variou de 0,94 (ensaio 1) a 47,6\% (ensaio 3).

A (Figura 1) apresenta a purificação da enzima amiloglicosidase pela resina DEAE-celulose em coluna de leito fixo, utilizando as condições estabelecidas no ensaio 3.

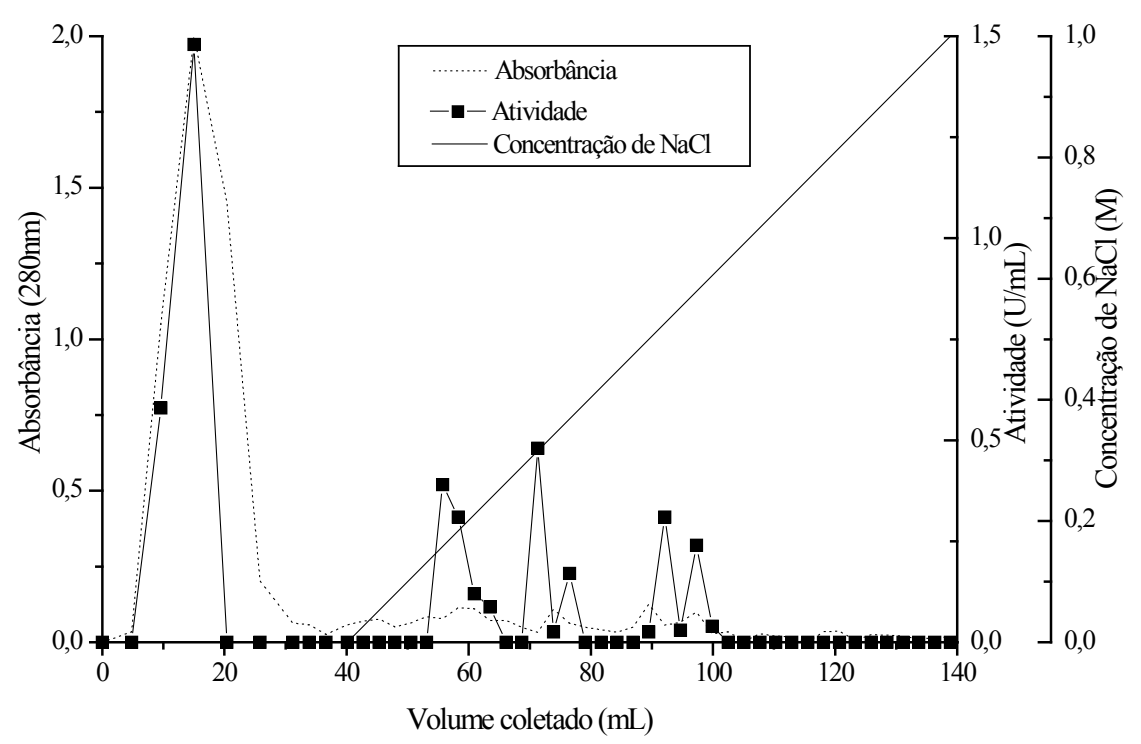

Figura 1. Cromatograma da purificação da amiloglicosidase em coluna de leito fixo de DEAE-celulose, com leito de $10 \mathrm{~cm}$ de altura, utilizando $8 \mathrm{~cm} / \mathrm{h}$ como velocidade de alimentação, $6 \mathrm{~mL}$ como volume de alimentação e trabalhando a $10^{\circ} \mathrm{C}$.

Foram alimentados $6 \mathrm{~mL}$ de extrato enzimático, após foi feita a lavagem da coluna para retirada das proteínas não adsorvidas com $32 \mathrm{~mL}$ de tampão Tris- $\mathrm{HCl}$ 0,025 M pH 8,0. A eluição foi realizada na forma de gradiente linear crescente e iniciou após a leitura de absorbância a $280 \mathrm{~nm}$ ter retornado a linha base. Ocorreram três picos de atividade enzimática, nas concentrações salinas entre 0,15 - 0,25 M, 0,32 0,37 M e 0,47 - 0,60 M, considerando a recuperação de cada pico, obteve-se $19,5 \%, 14,4 \%$ e $13,7 \%$, respectivamente.

Stamford et al. (2002) trabalhando com purificação de amiloglicosidase de Streptosporangium sp. também observaram saída de três picos com atividades de amiloglicosidase ao realizar cromatografia por permeação em gel. Chen, Zhang e Zhou (2005), purificaram amiloglicosidase de Chaetomium thermophilum através de fracionamento com sulfato de amônio, cromatografia de troca iônica e cromatografia de interação hidrofóbica, na etapa de purificação por cromatografia de troca iônica foi obtido um fator de purificação de 7,0 vezes e uma recuperação de $13,6 \%$.

Michelin et al. (2008) purificaram a amiloglicosidase de Paecilomyces variotii empregando a resina DEAE-celulose, os resultados obtidos por estes autores foram 20,7\% para a recuperação e 7,2 vezes para o fator de purificação.

Observa-se que os resultados obtidos neste trabalho são superiores aos encontrados na literatura 
para purificação da amiloglicosidase empregando cromatografia de troca iônica. Vale ressaltar que vários trabalhos (MICHELIN et al. 2008; CHEN; ZHANG; ZHOU, 2005) empregaram várias etapas para purificação da enzima, obtendo valores finais de fator de purificação e recuperação inferiores aos obtidos neste trabalho, onde purificou-se a enzima obtida diretamente do extrato bruto, através de uma única etapa de purificação.

Os parâmetros operacionais da etapa de purificação empregando cromatografia em coluna de troca iônica DEAE-celulose, da enzima amiloglicosidase de Aspergillus niger NRRL 3122, que resultaram em elevado fator de purificação e minimizaram as perdas da enzima foram, temperatura de $10^{\circ} \mathrm{C}$ e velocidade de alimentação de $8 \mathrm{~cm} / \mathrm{h}$. A adoção destas condições proporcionou uma recuperação de $47,6 \%$ e um fator de purificação de 9,9 vezes.

\section{Agradecimentos}

Ao apoio financeiro da Fundação de Amparo à Pesquisa do Estado do Rio Grande do Sul - FAPERGS.

\section{Referências}

BAUTISTA, L. F.; MARTÍNEZ, M.; ARACIL. J. Adsorption equilibrium of $\alpha$-amylase in aqueous solutions. AIChE Journal, New York, v. 45, n. 4, p. 761$768,1999$.

COSTA, J. A. V.; ALEGRE, R. M.; HASAN, S. D. M. Packing density and thermal conductivity determination for rice bran solid-state fermentation. Biotechnology Techniques, Heidelberg, v. 12, n. 10, p. 747-750, 1998.

CHEN, J.; LI, D. C.; ZHANG, Y. Q.; ZHOU, Q. X. Purification and characterization of a thermostable glucoamylase from Chaetomium thermophilum. The Journal of General and Applied Microbiology, Tokyo, v. 51, n. 3, p. 175-181, 2005.

GERBERDING, S. J.; BYERS, C. H. Preparative ionexchange chromatography of proteins from dairy whey. Journal of Chromatography A, Amsterdam, v. 808, n. 1/2, p. 141-151, 1998.

GHILDYAL, N. P.; RAMAKRISHNA, M.; LONSANE, B. K.; KARANTH, N. G. Efficient and simple extraction of mouldy bran in a pulsed column extractor for recovery of amyloglucosidase in concentrated form. Process Biochemistry, Amsterdam, v. 26, n. 4, p. 235-241, 1991.

GONZALES, C.; DELGADO, O.; BAIGORI, M.; ABATE, C.; DE FAGUEROA, L. I. C.; CALLIERI, D. A. Ethanol production from native cassava starch by a mixed culture of Endomycopsis fibuligera and Zymomonas mobilis. Acta Biotechnology, Hoboken, v. 18, n. 2, p. 149-155, 1998.

GOUVEIA, T.; KILIKIAN, B. V. Bioaffinity extraction of glucoamylase in aqueous two-phase systems using starch as free bioligand. Journal of Chromatography B, Amsterdam, v. 743, n. 1/2, p. 241-246, 2000.

LEVISON, P. R. Large scale ion-exchange column chromatography of proteins: comparison of different formats. Journal of Chromatography B, Amsterdam, v. 790, n. 1/2, p. 17-33, 2003.

LOWRY, O.; ROSEBROUGH, N.; FARR, L.; RANDALL, R. Protein measurement with the Folin phenol reagent. The Journal of Biological Chemistry, Bethesda, v. 193, n. 1, p. 265-275, 1951.

MANERA, A. P.; KAMIMURA, E. S.; BRITES, L. M.; KALIL, S. J. Adsorption of amyloglucosidase from Aspergillus niger NRRL 3122 using ion exchange resin. Brazilian Archives of Biology and Technology, Curitiba, v. 51, n. 5, p. 1015-1024, 2008.

MICHELIN, M.; RULLER, R.; WARD, R. J.; MORAES, L. A. B.; JORGE, J. A.; TERENZI, H. F.; POLIZELI, L. T. M. Purification and biochemical characterization of a thermostable extracellular glucoamylase produced by the thermotolerant fungus Paecilomyces variotti. Journal of Industrial Microbiology and Biotechnology, Heidelberg, v. 35 , n. 1, p. 17-25, 2008.

MILLER, G. L. Use of dinitrosalicylic acid reagent for determination of reducing sugar. Analytical Chemistry, Amsterdam, v. 31, p. 426-428, 1959.

PANDEY,A.; POONAM, N.; SOCCOL, C. R.; SOCCOL, V. T.; SINGH, D.; MOHAN, R. Advances in microbial amylases. Biotechnology and Applied Biochemistry, Indianapolis, v. 31, n. 2, p. 135-152, 2000.

SILVEIRA, S. T.; OLIVEIRA, M. S.; COSTA, J. A. V.; KALIL, S. J. Optimization of glucoamylase production by Aspergillus niger in solid-state fermentation. Applied Biochemistry and Biotechnology, Heidelberg, v. 128, n. 2, p. 131-139, 2006.

STAMFORD, T. L. M.; STAMFORD, N. P.; COELHO, L. C. B. B.; ARAÚJO, J. M. Production and characterization of a thermostable glucoamylase from Streptosporangium $s p$. endophyte of maize leaves. Bioresource Technology, Amsterdam, v. 83, n. 2, p. 105-109, 2002. 
WENZIG, E.; LINGG, S.; KERZEL, P.; ZEH, G.; MERSMANN, A. Comparison of selected methods for downstream processing in the production of bacterial lipase. Chemical Engineering \& Technology, Hoboken, v. 16, n. 6, p. 405-432, 1993. 
